\title{
The changing role of the primary school teacher in Swaziland in the context of HIV/AIDS: teacher as caretaker and economic provider.
}

NC. Nxumalo ${ }^{1}$,JM Wojcick ${ }^{i 2}$, MKM Magowe ${ }^{3}$

1 University of Swaziland, Faculty of Health Sciences, Mbabane, Kingdom of Swaziland

2 University of California, San Francisco, Department of Pediatrics, School of Medicine, San Francisco, United States

3 University of Botswana, School of Nursing, Gaborone, Botswana

Corresponding Author: Janet M Wojcicki

Email:wojcicki@gmail.com

\begin{abstract}
Swaziland has the world's highest HIV prevalence with $26 \%$ of adults aged 15-49 years living with HIV. There are approximately 17,000 Swazi children aged 0 to 14 years living with HIV. This qualitative study explored the experiences of Swazi teachers supporting learners living with or affected by HIV/AIDS, with a specific focus on the extent to which teachers are aware of the "Rights of the Child" in their teaching and approaches. Important themes emerged from thematic analysis including the following: teachers provided more than education to learners living with and affected by HIV, including material goods and additional time, in some cases at the expense of other learners. In the era of HIV/AIDS, the teacher has become the emotional caretaker and economic provider in addition to the predictable role of educator in Swaziland. Education curricula in HIV-burdened countries need to modify training programmes and support services available to teachers to accommodate the complex role that teachers play in caring for learners living with and affected by HIV.
\end{abstract}

\section{Background}

\section{$H I V$ and Education}

In a world where approximately 33.4 million people are estimated to be living with HIV, 1.8 million were children below 15 years of age in $2009^{1}$. Children represent the potential for a healthy society ${ }^{2}$ and need to be supported to benefit from their potential, yet they suffer an impact from HIV/AIDS and need more care and support from parents and teachers ${ }^{3}$. Classrooms that are highly burdened by HIV/ AIDS may pose additional challenges for teachers as they force educators to play multiple roles including teaching and possibly parenting and providing supportive health care 4 . Owing to the considerable time teachers spend with children, the onus often falls on teachers to provide care, treatment, emotional support, and counselling to children living with HIV in high-burden areas 5

With an HIV seroprevalence of $26 \%$ amongst adults aged $15-49$ years and $31.1 \%$ in women, ${ }^{6}$ Swaziland has the highest HIV prevalence in the world. Among pregnant women, $41.1 \%$ tested positive from the antenatal clinic survey in $2010^{7}$. Additionally, in children there were an estimated 17,000 cases in 2011 (0-14 years), ${ }^{8}$ mostly acquired either during birth or breastfeeding. Swaziland also has approximately 75,000 orphans aged $0-17$ years, as a result of the HIV/ AIDS pandemic. According to the Swaziland Demographic Health Survey (SDHS)6, 41.2\% of orphaned and vulnerable Children (OVC), including children living with HIV, received at least one type of basic external support while at school including medical, emotional, social/material and schoolrelated support. With the need for added support for learners in the context of HIV, it is necessary that teachers be enabled to be sensitive to these exceptional family circumstances, while operating within the rights of the child. If teachers are not specifically familiar with child rights, however, it may be difficult for teachers to integrate rights-based support to their already existing duties as educators. Previous studies have captured the lived experiences of primary school teachers, in areas of high HIV prevalence, who provide support to learners living with or affected by HIV in order to come up with recommendations to improve teacher support and develop an environment that is conducive for the children to focus on learning?. The context in which these teachers provided this support was not clear; neither was an assurance of the protection of the rights of the child, as declared by the United Nations.

\section{The UN Convention on the Rights of the Child}

The four core guiding principles of the United Nations Convention on the Rights of the Child ${ }^{10}$ (non-discrimination; devotion to the best interests of the child; the right to life, survival and development; and respect for the views of the child), which was ratified by the Swaziland government in 1995, were used as a conceptual framework to develop this study. The authors explored whether teachers, while providing support to learners living with and affected by HIV, were at all being guided indirectly by these principles, even if unaware of the UN Convention on the Rights of the Child.

\section{Methodology}

The UN Convention on the Rights of the Child ${ }^{10}$ guided the information elicited about experiences of teachers supporting learners living with and affected by HIV in selected primary schools in Swaziland in both in-depth interviews and a focus group discussion (FGD). Thematic analysis was carried out on transcripts of the in-depth individual interviews and FGD. Individual interviews were conducted with six primary school teachers from four schools selected from different areas in the Shiselweni, Manzini and Hhohho regions in Swaziland. Sampling of the teachers was purposive and based on the selection (inclusion/exclusion) criteria: the researcher interviewed teachers who have been in contact with learners living with or affected by HIV in their classrooms and were required to provide them with support in different ways. The schools from which the teachers were sampled were selected from a list of schools in which the Schools as Centers of Care and Support (SCCS) ${ }^{11}$ project has run in Southern Africa. SCCS is a model, which includes a multisectoral approach to addressing poverty, HIV/AIDS, and other infectious diseases. The schools were selected by convenience from clusters of schools included in the SCCS project. The individual interview participants included a head teacher, class teachers and guidance and counseling teachers. The focus group discussion had five teachers from two schools in one region (Shiselweni), which included a deputy head teacher, class teachers and guidance and counseling teachers. There were both male and female teachers in the sample and four females and one male in the focus group. 
The teachers who participated in the individual interviews were not part of the FGD.The individual interviews and FGD were carried out by the principal investigator with the assistance of a research assistant. The individual interviews ranged from 45 minutes to over one hour long. The FGD lasted two hours. Interviews were conducted in English and SiSwati, the two most spoken languages in Swaziland. The questions were first asked in SiSwati, then translated to English for clarity, and participants responded in both English and SiSwati. All interviews were tape-recorded and transcribed verbatim in English, with some SiSwati terms that would lose meaning if translated to English being retained. The transcribed interviews were read in totality to get an understanding of the whole experience of teachers in accordance with the thematic analysis method of Braun and $\mathrm{Clarke}^{12}$. Subsequently, categories were singled out and related to each other to form major themes. These themes were chosen based on the initial goals of the study as well as those that developed organically through the interviews and the FGD. Four of the arising themes are discussed in this paper. The themes-(1) the teacher as a caretaker, (2) sexual violence and devotion to the best interests of the child, (3) the teacher as an economic provider, and (4) the extra hours to support those with HIV/AIDS in the classroom-were chosen because they change the overall role, responsibilities and scope of work of the primary school teacher in Swaziland in the context of HIV/AIDS. Relations between these themes were explored further and recommendations are made as conclusions.

All research was approved by the Ethics Board in the Ministry of Education in the Kingdom of Swaziland.

\section{Results}

All the teachers had initial teacher training in Swaziland and qualified with either diplomas (from colleges) or degrees (from four-year universities); they all had experience with learners living with or affected by HIV. The teachers were all adults above the age of 21 years, they taught grades one to seven, and their teaching experience ranged from six to 37 years. Qualitative data from the individual interviews and the focus group discussion are outlined in detail below.

\section{The teacher as a caretaker: Devotion to the best interests of the child and providing a classroom with non-discrimination}

In Swaziland, teachers now act as child advocates whose roles include sharing information, such as how to self-care and medicate to empower learners in the face of difficult home and community circumstances, such as the absence of parental or adult support at home. The head teacher of one of the schools states that she had to think comprehensively about the best interests of the child (thinking broadly of mental and physical health in conceptualizing "best interest of the child"):

I think I provide what we call 'tender care'... I have to ask if they have eaten, when does he/she take his/her drugs... now you should drink your medication.

In other instances, teachers have been placed in situations where they take sick children to the hospital or clinic, because the child does not have a reliable caretaker at home. In these scenarios, they educate the rest of the class about not stigmatizing individuals living with HIV/AIDS and emphasize that HIV should not be treated any differently than any other health condition:

Here at school... we talked that a person has the right to be treated.. taken to hospital... without looking at just HIV.

Another teacher described the importance of not making the individuals living with or affected by HIV feel different from others, which is also related to the overall process of removing the stigma from children living with HIV/ AIDS and educating the class in this realm. Although the teachers did not specifically state they were providing a nondiscriminatory policy in line with the rights of the child, their words embody these values:

Don't specialize (call attention)... maybe you are giving clothes... you are going to give this particular child... then give the others in class... because they feel bad that they are being given handouts... even with food... they don't want to come and collect even though they need it; they do not want to be exposed.

While these teachers focus on the importance of not stigmatizing children living with HIV/AIDS, none had been specifically provided with education or training on how to address or teach a classroom with children living with HIV/ AIDS.

\section{Sexual violence and devotion to the best interests of the child}

Learners who are living with or affected by HIV may have been exposed to neglect and sexual abuse in their communities, resulting in HIV seroconversion. Clearly, any type of sexual abuse denies children their right to protection from all forms of violence, as articulated in the Rights of the Child (Article 19) (UN CRC, 1989). Teachers emphasized the need to be vigilant in order to identify the learners who are abused or neglected at home or in the community. Although they again did not directly articulate the "Rights of the Child" in interviews and discussions, the teachers, in their statements, embodied commitment and devotion to the best interests of the child.

One teacher discussed these issues, mentioning that teachers have to be alert to the possibility that children may vocalize these problems in indirect ways:

Try to be... always alert, be sensitive to see that today this child is not walking like yesterday... we must be a bridge-gap between the bome and the school environment... In this community ... people drink in the bomesteads... it is a burden (difficult) because the children cannot speak for themselves... they just sit down and cry.

Students may alter their in-class behaviours because of issues of HIV/AIDS at home, including potentially issues of sexual violence, and the teacher has to be alert to subtle changes. The teachers below indicate in the interviews that Swazi teachers have to be sensitive and aware of the rights and the views of the child:

At times you find that they sleep in class... because she has to do a lot of things at home... before and after school.

I will say... the affected ones are really having a burden because they are even disturbed academically, even a child who was doing well declines.

A participant from the focus group discussion had a similar thought:

They come in private... like the one who ended up telling me that her grandfather was abusing her.

Another teacher mentioned that other times children can be very direct and confide all the specifics of the problems as stated below:

They stayed with their grandmother who returned home late drunk... her biological father came in and raped them all. 


\section{The teacher as an economic provider}

The teachers indicated that their role and scope of work have broadened further to include being a provider for learners in a resource-limited setting such as Swaziland. Teachers in Swaziland, in addition to taking on the academic and psychological caretaker roles described above, also assist with the provision of food and clothing, which enables the learners to perform better academically as described below. Teachers that participated in the current study explained their provider role and the effect it has on them.

One teacher stated how her daily routine involved assessing who had eaten and who had not yet eaten:

Even in the morning you look at them and see a child who has not eaten and you have to make means to get food for him/ her so that they can be able to learn and [keep] up with the others.

Another participant made a similar point:

There are teachers who look at the children in the morning; they get breakfast to help those who are taking medication... so that they don't take it on an empty stomach.

A head teacher described the extent they usually have to go to meet the needs of the learners:

Sometimes I give the child food, uniform, books, whatever it is they need at that time.

Teachers have gone so far as to change the policies at the schools and re-structure the hours and availability of the school kitchens to accommodate the needs of the children. One participant in a focus group discussion noted:

We ended up... talking to the principal then there was an arrangement for them in the school kitchen... that at least they should eat before they go to classes].

Teachers stated that being a provider for the learners living with and affected by HIV did not only drain them materially and financially but was also an emotionally taxing experience:

It then requires that you take your own time, maybe break time to take care of those children... It is too much work now.

Another teacher described the myriad responsibilities that now fell on the shoulders of the teachers:

They said we must try to take care of everything...they said you take care of the child spiritually, mentally, physically and material wise.

Often times there is a lack of food from the school-feeding scheme, especially to feed individual learners in the morning, so some teachers may use their own resources. A group of teachers had taken it upon themselves in one school to take care of the children who came to school hungry, or needed medical attention as described below during the focus group discussion:

What we do now, we give them what we can... When we cannot do anything we send them to the principal... We don't even send them home... We hit (take) from our pockets... We hit petrol... We hit everything.

There is no fund at school for such things... and it's not all teachers... It's just those who feel it.

The teachers in the focus group differed on the extent of the resources, which should be provided to children paid for by the teacher. Four of the five teachers felt compelled to use family resources to pay for the learners where the last teacher wanted to help the children but did not want to use personal resources.
The extra hours to support those living with HIV/AIDS in the

\section{classroom}

The teachers interviewed stated that, as they are now busy caring for those who are in need of added attention (children living with HIV/AIDS), there is a possibility that the rest of the learners suffer neglect. With the special attention they have to give to HIV-affected learners, Swazi teachers are overworked and are without adequate support. The teachers illustrated these problems in the following statements:

If our economy wasn't failing... they would increase the number of teachers. There is a lot [required of] the teacher. These children [living with HIV] - they need to have time to sit down, just to build them spiritually... Where are the others and their lessons at that time?

As a teacher you also get disturbed in your class as you teach because you will find that the child is weak... you cannot proceed with teaching.

A slightly different perspective came from the FGD: one participant emphatically stated that she would care for a sick learner in the classroom but also wanted the caregiver at home to take responsibility and look after the child. This teacher took the initiative to visit the sick child's house and discuss the issue with the adult guardian.

She challenged the adult caregiver while visiting the home:

We got there [to the house] and we said 'your child comes to school and you know he is not well... what do you want us to do with him?

In some cases, such as this one, teachers have to take the advocacy role and ensure that some of the rights of the child are fulfilled, as with this child, the right to life and development and the best interests of the child. Swazi teachers may not necessarily be provided with adequate training and support to address the needs of these learners. The following teacher illustrated this point as she struggled to be able to relate to what the child was experiencing:

You think of yourself as a person that... you know... old as I am... the child is experiencing things that are above her... you just wish you could get into her shoes.

\section{Discussion}

Expanded responsibilities and role of the Swazi primary school teacher Our study has shown that in countries, like Swaziland, with a high burden of HIV/AIDS, educators take on a redefined scope of work and additional responsibilities in the classroom including that of emotional caregiver and provider of material support. Children who have lost primary caregivers may need the protection of the school environment to develop mentally and physically. In recognition of the tremendous personal efforts that teachers and schools have made in providing much needed care and support for learners, the educational system should tap into this resource and provide teachers with the support and training they need. Our focus group and individual discussions indicate that the expanded definition of the teacher in the Swazi context is not associated with increased monetary benefits or added training. Unfortunately, in a resource-poor setting such as Swaziland, these elements must be self-taught and teachers must also use their limited means to support.

When a child's health and physiological needs are not met, their ability to attend school is compromised and their potential for personal development is undermined. In Swaziland, this is the case with many children living with HIV In some countries in Sub-Saharan Africa, including South Africa, there are resources to provide teachers with additional training, including e-learning courses and additional short 
learning courses to support teachers who are working in high-burden HIV settings. It is not clear, however, how these courses are financed, and they are not widely available in all areas $^{13}$. Some intervention programmes can help teachers encourage resilience in the schools by creating networks with community service providers. By providing access to additional resources, these programmes have been successful in mitigating against risks and difficulties encountered daily by learners and providers ${ }^{14}$. Additionally, these programmes have helped empower teachers by encouraging them to develop action plans and use the school as an organizational base to link up with the community and as a safe zone against adversity in the environment ${ }^{14}$.

Our study, like others, has shown that, even without training, teachers are incorporating HIV care into the school environment $t^{15}$. These teachers are, however, over-burdened and stressed by the environment. Wood and Goba examined teachers' responses to dealing with orphans and vulnerable children in the schools and revealed that some teachers felt stress over the added responsibility ${ }^{16}$. In places such as Swaziland and other areas of southern Africa, teachers may have additional home responsibilities because of the HIV/ AIDS epidemic including family members living with HIV, and some may be living with HIV themselves. Beyers and Hay noted that teachers cognitively recognize their need to support and nurture learners impacted by HIV/AIDS but emotionally may not have the preparation or resources to successfully provide this necessary service ${ }^{17}$.

\section{Teaching and principles of the United Nations Rights of the Child}

We found that while many of the Swazi teachers had limited additional training or resources to address the responsibilities of teaching in high-burden HIV/AIDS areas, many responded to the situation by incorporating principles of the United Nations Rights of the Child into their work as primary school teachers. Specifically, through a policy of non-discrimination, looking out for the best interests of the child and the right to live, these Swazi teachers are advancing not only child health but also using a framework that has the potential to alleviate poverty in the future as outlined by Pemberteon ${ }^{18}$. Furthermore, recommendations that have grown out of the UN Rights of the Child, including those by Schraeder include to "invest in providing support services for trained teachers to sustain and improve education on HIV and AIDS", ${ }^{19}$ are similar to the recommendations that we make for Swaziland. In Swaziland, the definition of "teacher" differs from the definition in places where HIV/ AIDS does not play such a large role in daily life.

\section{Conclusion}

Swaziland aspires for "an HIV-free generation", as suggested by television advertisements and other public service announcements, but in addition to focusing on prevention of HIV infection, additional efforts need to be targeted towards caring for the generations currently living with and affected by HIV. Until the target of an HIV-free generation is reached, these individuals should be physically, emotionally, mentally, socially and spiritually prepared for a full life, as people treated with antiretroviral therapies have the opportunity to participate as active members of society now. Primary school teachers in Swaziland, as indicated by our research, provide every effort to support learners impacted by HIV/ AIDS so that they can be well-rounded adults in the future. However, there must be educational and social support for Swazi teachers who may be poorly prepared, not trained, or not provided with the resources for the increasing scope of work of the primary school teacher. Currently, resources in the schools are insufficient and sometimes families are not supportive. Even without the necessary education and training, however, we found that teachers were embodying many of the principles of the United Nations Rights of the Child including non-discrimination, devotion to the best interests of the child and child's right to live. Interventions similar to those provided in South Africa, which have successfully linked teachers with service providers in the community and have provided a greater network of support for teachers and learners could be applied in Swaziland and other nations similarly burdened by the HIV/AIDS epidemic ${ }^{14}$.

\section{Acknowledgements}

The authors would like to acknowledge the Guidance and Counselling Department in the Ministry of Education, and the School Health Programme in the Ministry of Health for assisting in the conceptualization of the study and sampling of the schools where the study was conducted. We also appreciate the teachers who gave of their time to participate in the study, and the University of Botswana and School of Nursing Lecturers for supervising the research.

\section{References}

1. Joint United Nations Programme on HIV/AIDS (UNAIDS) (2001). Annual report 2009. Retrieved from http://www.unaids.org/sites/ default/files/media_asset?2009_annual_report_en_).pdf, accessed December 10, 2014 .

2. Pender NJ, Murdaugh CL and Parsons MA. Health Promotion in Nursing Practice (5th Ed.). Upper Saddle River: 2006; Pearson Prentice Hall.

3. Skinner EA and Zimmer-Gembeck MJ. The Development of Coping. Annual Review of Psychology 2007; 58, 119-144.

4. Thobela, N.R., (2009). The perceptions of principals and teachers of learners with HIV/AIDS. Thesis, Stellenbosch University Retrieved from http://scholar.sun.ac.za/bitstream/handle/10019.1/1909, accessed December 10, 2014

5. Nzioka, C., Ramos, L., (2008). Training teachers in an HIV/AIDS context: Experiences from Ethiopia, Kenya, Uganda and Zambia. International Institute for Educational Planning, UNESCO, IIEP: Paris. http://unesdoc.unesco.org/images/0016/001636/163605e.pdf, accessed December 10, 2014

6. Swaziland Central Statistical Office. Swaziland demographic and health survey, 2006-7: Central Statistical Office, May 2008: Mbabane, Swaziland. https://hsprogram.com/pubs/pdf/FR202/FR202.pdf, accessed December 10, 2014

7. National HIV Prevention Policy, 2012. Swaziland Ministry of Health. Mbabane, Swaziland. https:/www.k4health.org/sites/default/ files/preventionpolicy_0.pdf, accessed December 10, 2014.

8. UNICEF Humanitarian Action, Swaziland in 2007. www.unicef. org/har07/files/countrychap_Swaziland.pdf, accessed December 10, 2014.

9. UNICEF. Schools as Centres of Care and Support: conceptual framework. UNICEF, 2008: Swaziland Government.

10. UNICEF Convention on the Rights of the Child, (20 November 1989). General Assembly Resolution 44/25. www.unicef.org/ sowc2012/pdfs/SOWC-2012-The-Convention-on-the_Rights-of-theChild.pdf, accessed December 10, 2014.

11. Association for the Development of Education in Africa. Schools as Centers of Care and Support: Responding to the Needs of Orphans and Other Vulnerable Children in Rural Areas. ADEA 2009, http:// 
www.steppingstonesfeedback.org/resources/14/ADEA_SCCS_Africa_ CaseStudy.pdf, accessed December 10, 2104.

12. Braun V and V Clarke. Using Thematic Analysis in Psychology. Qualitative Research in Psychology 2006; 3: 77-101.

13. Holderness WL Equipping educators to address HIV and AIDS: A Review of Selected Teacher Education Initiatives. SAHARA-J: Journal of Social Sciences 2012; 9:S1, 48-55.

14. Ebersohn L and R Ferreira. Coping in an HIV/AIDS-dominated context: teachers promoting resilience in the schools. Health Education Research 2011; 26(4): 596-613.

15. Betancourt TS, Fawzi M, KS Bruderlein, C Desmond, Kim JY. Children affected by HIV/AIDS: SAFE, a model for promoting their security, health, and development. Psychology, Health \& Medicine 2010; 15:3, 243-265.
16. Wood, L.A and Goba, L. Care and support of orphaned and vulnerable children at school: helping teachers to respond. South African Journal of Education 2011; 31:275-290.

17. Beyers C and Hay J. Supporting HIV positive learners in inclusive classes in South Africa: is it the responsibility of teachers? Journal of Social Sciences 2011; 26:2, 99-104.

18. Pemberton S, Gordon D, Nandy S, Pantazis C, Townsend S. Child Rights and Poverty: Can the International Framework of Childs Right be Used to Improve Child Survival Rates? PLOS Medicine 2007; 4(10): e307.

19. McMillan Schraeder A and D Simkiss. The United Nations Convention on the Rights of the Child and HIV/AIDS Journal of Tropical Pediatrics 2009, 55(2): 71-2. 